\title{
Preservation of kidney function irrelevant of total kidney volume growth rate with tolvaptan treatment in patients with autosomal dominant polycystic kidney disease
}

\author{
Shigeo Horie ${ }^{1,2}$ (D) $\cdot$ Satoru Muto ${ }^{1,2} \cdot$ Haruna Kawano $^{1,2} \cdot$ Tadashi Okada $^{3} \cdot$ Yoshiyuki Shibasaki $^{4} \cdot \mathrm{Koji} \mathrm{Nakajima}^{4}$. \\ Tatsuki Ibuki ${ }^{4}$
}

Received: 2 June 2020 / Accepted: 2 December 2020 / Published online: 20 January 2021

(c) The Author(s) 2021

\begin{abstract}
Background Tolvaptan slowed the rates of total kidney volume (TKV) growth and renal function decline over a 3-year period in patients with autosomal dominant polycystic kidney disease (ADPKD) enrolled in the Tolvaptan Efficacy and Safety in Management of Autosomal Dominant Polycystic Kidney Disease and Its Outcomes (TEMPO) 3:4 trial (NCT00428948). In this post hoc analysis of Japanese patients from TEMPO 3:4, we evaluated whether the effects of tolvaptan on TKV and on renal function are interrelated.

Methods One hundred and forty-seven Japanese patients from TEMPO 3:4 were included in this analysis (placebo, $n=55$; tolvaptan, $n=92)$. Tolvaptan-treated patients were stratified into the responder group $(n=37)$, defined as tolvaptan-treated patients with a net decrease in TKV from baseline to year 3, and the non-responder group $(n=55)$, defined as tolvaptantreated patients with a net increase in TKV.

Results Mean changes during follow-up in the placebo, responder, and non-responder groups were $16.99 \%,-8.33 \%$, and $13.95 \%$, respectively, for TKV and $-12.61,-8.47$, and $-8.58 \mathrm{~mL} / \mathrm{min} / 1.73 \mathrm{~m}^{2}$, respectively, for estimated glomerular filtration rate (eGFR). Compared with the placebo group, eGFR decline was significantly slowed in both the responder and non-responder groups $(P<0.05)$.

Conclusion Tolvaptan was effective in slowing eGFR decline, regardless of TKV response, over 3 years in patients with ADPKD in Japan. Treatment with tolvaptan may have beneficial effects on slowing of renal function decline even in patients who have not experienced a reduction in the rate of TKV growth by treatment with tolvaptan.
\end{abstract}

Keywords Autosomal dominant polycystic kidney disease $\cdot$ Glomerular filtration rate $\cdot$ Japan $\cdot$ Tolvaptan $\cdot$ Total kidney volume

Supplementary Information The online version contains supplementary material available at https://doi.org/10.1007/s1015 7-020-02009-0.

Shigeo Horie

shorie@juntendo.ac.jp

1 Department of Urology, Juntendo University Graduate School of Medicine, 2-1-1 Hongo, Bunkyo-ku, Tokyo 113-8421, Japan

2 Department of Advanced Informatics for Genetic Diseases, Juntendo University Graduate School of Medicine, Tokyo, Japan

3 Department of Clinical Development, Otsuka Pharmaceutical Co., Ltd, Osaka, Japan

4 Medical Affairs, Otsuka Pharmaceutical Co., Ltd, Tokyo, Japan

\section{Introduction}

Autosomal dominant polycystic kidney disease (ADPKD) is an inherited disease characterized by age-dependent development of multiple cysts in the kidneys, causing a gradual and irreversible expansion of kidney volume [1]. ADPKD eventually leads to end-stage renal failure and the need for renal replacement therapy in a majority of patients, typically by the fifth or sixth decade of life [2]. Natural history data on the gradual expansion of total kidney volume (TKV) in ADPKD are available, including 8 years of follow-up from the prospective, observational Consortium for Radiologic Imaging Studies of Polycystic Kidney Disease (CRISP) I and II studies [1, 3, 4]. TKV and glomerular filtration rate (GFR) are markers of ADPKD progression, with TKV used 
as a prognostic indicator early in the disease course, prior to significant changes in renal function [4]. Tolvaptan, a vasopressin $\mathrm{V}_{2}$-receptor antagonist, suppresses binding of vasopressin to the $\mathrm{V}_{2}$-receptor in renal epithelial cells, and vasopressin $\mathrm{V}_{2}$-receptor blockade has been shown, in animal models of ADPKD, to inhibit the growth of renal cysts and the decline in renal function [5-9]. In the Tolvaptan Efficacy and Safety in Management of Autosomal Dominant Polycystic Kidney Disease and Its Outcomes (TEMPO) 3:4 clinical trial, a global, multicenter study that included patients from Japan, tolvaptan slowed the rates of TKV growth and renal function decline over a 3-year period compared with placebo in patients with ADPKD [10,11].

In this post hoc analysis of patients enrolled in TEMPO 3:4 in Japan, we assessed the patterns of TKV response to tolvaptan in ADPKD and explored the factors potentially predictive of TKV response, such as baseline ADPKD risk class [12]. Further, we evaluated possible correlations between the effects of tolvaptan on TKV growth rate and on renal function decline.

\section{Materials and methods}

\section{Study design}

This study is a post hoc analysis of the Japanese population from TEMPO 3:4, a multicenter, double-blind, placebocontrolled, 3-year clinical study (ClinicalTrials.gov number, NCT00428948) [10, 11]. Patients were enrolled at 129 sites worldwide. Study design, setting, data collection, and enrollment criteria have been previously described in detail [10, 13]. Briefly, eligible patients were aged $18-50$ years, with a diagnosis of ADPKD by the Ravine criteria, TKV $\geq 750 \mathrm{~mL}$ as measured by magnetic resonance imaging (MRI), and estimated creatinine clearance $(\mathrm{Ccr}) \geq 60 \mathrm{~mL} / \mathrm{min}$. Patients were randomly assigned in a 2:1 ratio to receive tolvaptan or placebo. Study drug was titrated from a daily split dose of 45/15 mg-60/30 mg and 90/30 mg based on patient-reported tolerability. After the titration phase, patients took the highest dose tolerable for 36 months. The primary endpoint was the annual rate of change in TKV from baseline; secondary endpoints included a composite of time to clinical progression (defined as worsening kidney function, kidney pain, hypertension, and albuminuria) and rate of kidney function decline.

TEMPO 3:4 was conducted in accordance with the ethical principles originating in the Declaration of Helsinki and in compliance with good clinical practice guidelines. The protocol was approved by the institutional review board at each trial site. Written informed consent was obtained from all participants.

\section{Objectives}

The objectives of this post hoc analysis were to compare the change in TKV from baseline to year 3 among the placebo, responder, and non-responder groups; identify the factors predictive of decrease in TKV; and explore the correlations between changes in TKV and kidney function.

\section{Patients}

Patients who completed the TEMPO 3:4 trial in Japan were stratified into three groups: (1) placebo-treated patients; (2) responders, defined as tolvaptan-treated patients with a net decrease in TKV from baseline to year 3; and (3) non-responders, defined as tolvaptan-treated patients who showed a net increase in TKV.

\section{Evaluations}

Data from the end of the tolvaptan titration phase were used for baseline kidney function values. Ccr was calculated by the Cockcroft-Gault formula [14]. Calculation of estimated glomerular filtration rate (eGFR; $\mathrm{mL} / \mathrm{min} / 1.73 \mathrm{~m}^{2}$ ) was performed as follows by two formulae: eGFR by the Chronic Kidney Disease Epidemiology Collaboration (CKD-EPI) equation modified for Japanese $=0.813$ (Japanese coefficient $) \times 141 \times$ minimum (serum creatinine $/ \kappa$ or 1$)^{\alpha} \times$ maximum (serum creatinine/ $\kappa$ or 1$)^{-1.209} \times 0.993^{\mathrm{Age}} \times 1.018$ (if female) $\times 1.159$ (if black) ( $\kappa$ is 0.7 for females and 0.9 for males, $\alpha$ is -0.329 for females and -0.411 for males) [15] and eGFR by the Japanese eGFR equation based on serum creatinine (eGFR-J) developed by the Japanese Society of Nephrology $=194 \times$ serum creatinine ${ }^{-1.094} \times$ age $^{-0.287}$ (if male) and $194 \times$ serum creatinine $e^{-1.094} \times$ age $^{-0.287} \times 0.739$ (if female) [16]. Chronic kidney disease stage was classified based on GFR [17].

Baseline MRI data were assessed in blinded reads to categorize patients into ADPKD risk classes according to prespecified imaging criteria [12]. Patients were categorized as class 1 (typical ADPKD) or class 2 (atypical ADPKD), with class 1 patients further stratified into five subclasses $(1 \mathrm{~A}-1 \mathrm{E})$ based on height-adjusted TKV (htTKV) and age. The estimated annual kidney growth rates for each subclass are $<1.5 \%$ (1A), $1.5-3.0 \%$ (1B), 3.0-4.5\% (1C), 4.5-6.0\% (1D), and $>6.0 \%$ (1E), with a theoretical initial htTKV of $150 \mathrm{~mL} / \mathrm{m}$. In the analysis of predictive factors for change in TKV, ADPKD risk class was expressed on an ordinal scale from class 1B to $1 \mathrm{E}$.

\section{Statistical analysis}

The proportions of patients with a net decrease in TKV from baseline to year 3 in the placebo and tolvaptan groups 
were compared by the chi-square test. Factors affecting decrease in TKV were analyzed by univariate logistic regression, with calculation of odds ratio (OR), 95\% confidence interval (CI), and $P$ values. The covariates analyzed included demographic characteristics, stratification factors, medical history, current medication, polycystic kidney disease characteristics, and kidney function parameters. Factors found to be significant were further analyzed in a multiple logistic regression model.

To evaluate the correlations between changes in TKV and changes in kidney function parameters from baseline to year 3, Pearson's correlation coefficient $(r)$, simple regression analysis parameter estimate, standard error, 95\% CI, and $P$ value were calculated. Changes in TKV, kidney function, and urine osmolality from baseline to year 3 were compared among the placebo and tolvaptan groups using Tukey-Kramer's honestly significant difference test.

Statistical significance was defined as $P<0.05$. All statistical analyses were performed using SAS 9.4 and JMP 13 (SAS Institute, Cary, North Carolina).

\section{Results}

\section{Patient characteristics}

One hundred and forty-seven Japanese patients from the TEMPO 3:4 trial were included in this analysis (placebo, $n=55$; tolvaptan, $n=92$ ). By ADPKD risk classification, $9.5 \%$ of patients were class $1 \mathrm{~B}, 40.8 \%$ class $1 \mathrm{C}, 30.6 \%$ class $1 \mathrm{D}$, and $16.3 \%$ class $1 \mathrm{E}$. Tolvaptan-treated patients were stratified into responders $(n=37)$, defined as patients who achieved a net decrease in TKV from baseline to year 3 , or non-responders $(n=55)$, defined as patients who experienced a net increase in TKV from baseline to year 3 (Fig. 1). Patient characteristics and demographic data in the placebo, responder, and non-responder groups are shown in Table 1. The distribution of patients in each risk subclass was similar between the placebo and tolvaptan groups (Fig. 2). Overall, $40.2 \%$ (37/92) of tolvaptan-treated patients, compared with 5.5\% (3/55) of placebo-treated patients, experienced a net decrease in TKV from baseline to year $3(P<0.0001)$. Tolvaptan was associated with decreased TKV in $60 \%$ of

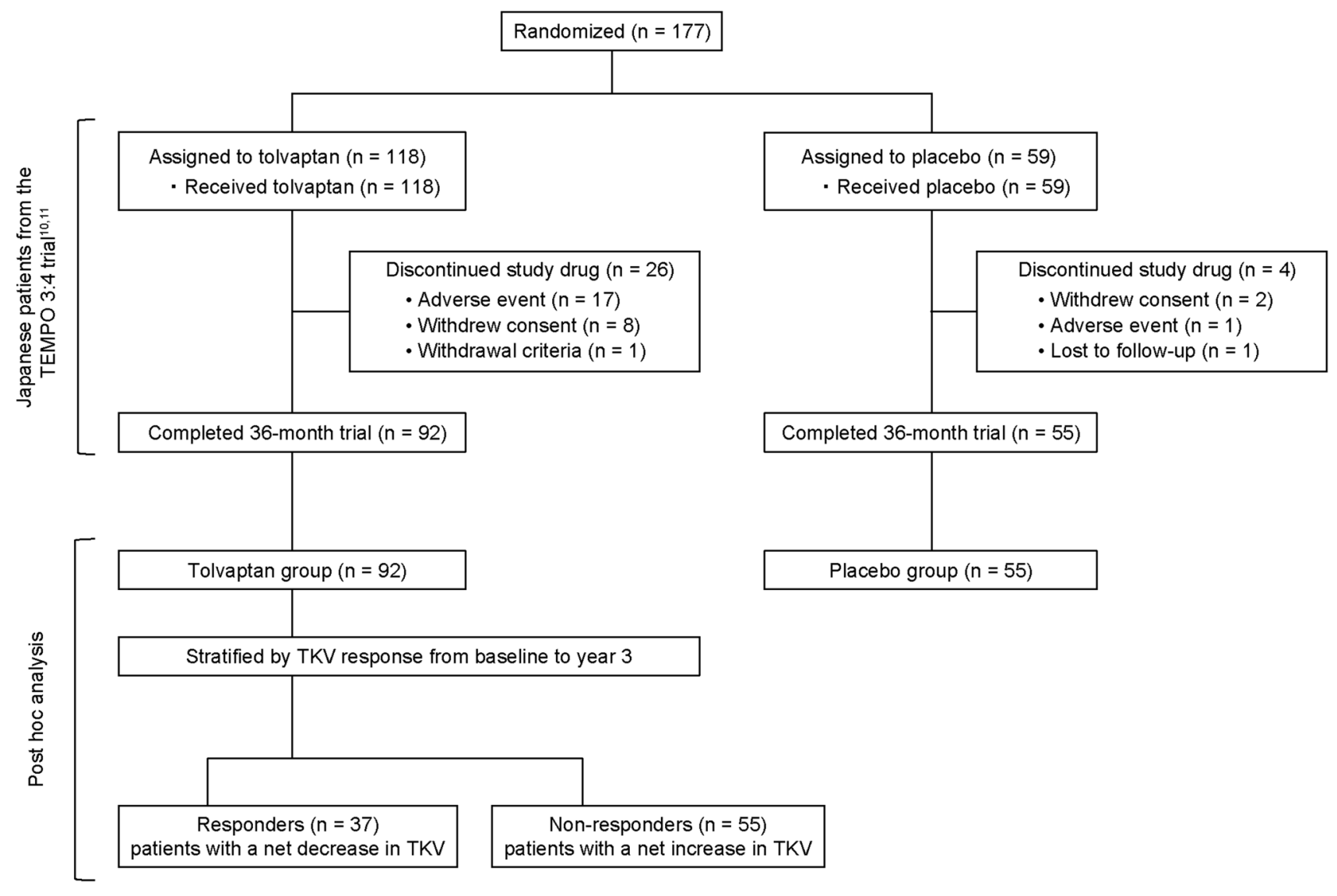

Fig. 1 Patient flow and analysis set. Patients who received tolvaptan in the TEMPO 3:4 trial in Japan were stratified into two groups. TKV total kidney volume 
Table 1 Patient characteristics and demographic data

\begin{tabular}{|c|c|c|c|}
\hline & \multirow{2}{*}{$\begin{array}{l}\text { Placebo }(n=55) \\
\text { Placebo group } \\
(n=55)\end{array}$} & \multicolumn{2}{|l|}{ Tolvaptan $(n=92)$} \\
\hline & & $\begin{array}{l}\text { Responders group } \\
(n=37)\end{array}$ & $\begin{array}{l}\text { Non-responders group } \\
(n=55)\end{array}$ \\
\hline \multicolumn{4}{|l|}{ Demographic characteristic } \\
\hline Sex (male) & $33(60.0)$ & $12(32.4)$ & $36(65.5)$ \\
\hline Age (years) & $40.5 \pm 5.6$ & $39.7 \pm 5.4$ & $38.1 \pm 6.5$ \\
\hline Height $(\mathrm{cm})$ & $169.5 \pm 6.9$ & $164.0 \pm 8.8$ & $169.3 \pm 8.2$ \\
\hline Weight (kg) & $66.4 \pm 13.1$ & $61.2 \pm 12.5$ & $69.2 \pm 12.2$ \\
\hline $\operatorname{BMI}\left(\mathrm{kg} / \mathrm{m}^{2}\right)$ & $23.0 \pm 3.4$ & $22.6 \pm 2.9$ & $24.0 \pm 3.3$ \\
\hline \multicolumn{4}{|l|}{ Polycystic kidney disease characteristic } \\
\hline Systolic blood pressure (mm Hg) & $125.4 \pm 12.8$ & $123.2 \pm 12.2$ & $127.4 \pm 14.6$ \\
\hline Diastolic blood pressure (mm $\mathrm{Hg})$ & $80.8 \pm 9.8$ & $79.5 \pm 11.3$ & $81.9 \pm 14.1$ \\
\hline Mean blood pressure $(\mathrm{mm} \mathrm{Hg})$ & $95.7 \pm 10.0$ & $94.1 \pm 11.0$ & $97.0 \pm 13.2$ \\
\hline $\mathrm{TKV}(\mathrm{mL})$ & $1582.2 \pm 643.8$ & $1434.3 \pm 640.6$ & $1518.9 \pm 559.8$ \\
\hline Height-adjusted TKV (mL/m) & $928.5 \pm 362.1$ & $871.7 \pm 377.9$ & $897.7 \pm 327.3$ \\
\hline $\mathrm{Cr}(\mathrm{mg} / \mathrm{dL})$ & $0.97 \pm 0.27$ & $0.95 \pm 0.32$ & $1.03 \pm 0.32$ \\
\hline $1 / \mathrm{Cr}\left[(\mathrm{mg} / \mathrm{mL})^{-1}\right]$ & $111.7 \pm 33.7$ & $115.7 \pm 34.4$ & $106.4 \pm 32.4$ \\
\hline $\operatorname{Ccr}(\mathrm{mL} / \mathrm{min})^{\mathrm{a}}$ & $93.1 \pm 23.1$ & $84.3 \pm 21.8$ & $95.1 \pm 27.0$ \\
\hline eGFR CKD-EPI $\left(\mathrm{mL} / \mathrm{min} / 1.73 \mathrm{~m}^{2}\right)^{\mathrm{b}}$ & $73.7 \pm 16.4$ & $71.3 \pm 17.2$ & $72.0 \pm 17.7$ \\
\hline eGFR-J $\left(\mathrm{mL} / \mathrm{min} / 1.73 \mathrm{~m}^{2}\right)^{\mathrm{c}}$ & $66.3 \pm 17.1$ & $63.6 \pm 16.5$ & $65.0 \pm 17.0$ \\
\hline Urine albumin-to-creatinine ratio & $10.7 \pm 18.3$ & $7.5 \pm 7.8$ & $11.2 \pm 16.5$ \\
\hline CysC (mg/L) & $0.77 \pm 0.19$ & $0.76 \pm 0.20$ & $0.80 \pm 0.20$ \\
\hline Urine osmolality (mOsm/kg) & $475.0 \pm 137.1$ & $440.8 \pm 140.6$ & $465.7 \pm 151.2$ \\
\hline \multicolumn{4}{|l|}{ CKD stage ${ }^{\mathrm{d}}$} \\
\hline G1 & $3(5.5)$ & $2(5.4)$ & $5(9.3)$ \\
\hline G2 & $31(56.4)$ & $20(54.1)$ & $25(46.3)$ \\
\hline G3a & $17(30.9)$ & $8(21.6)$ & $18(33.3)$ \\
\hline $\mathrm{G} 3 \mathrm{~b}$ & $4(7.3)$ & $7(18.9)$ & $6(11.1)$ \\
\hline G4 & $0(0.0)$ & $0(0.0)$ & $0(0.0)$ \\
\hline G5 & $0(0.0)$ & $0(0.0)$ & $0(0.0)$ \\
\hline \multicolumn{4}{|l|}{ ADPKD risk classification $^{\mathrm{e}}$} \\
\hline $1 \mathrm{~A}$ & $0(0.0)$ & $0(0.0)$ & $0(0.0)$ \\
\hline 1B & $4(7.3)$ & $6(16.2)$ & $4(7.3)$ \\
\hline $1 \mathrm{C}$ & $26(47.3)$ & $13(35.1)$ & $21(38.2)$ \\
\hline $1 \mathrm{D}$ & $17(30.9)$ & $11(29.7)$ & $17(30.9)$ \\
\hline $1 \mathrm{E}$ & $8(14.5)$ & $3(8.1)$ & $13(23.6)$ \\
\hline $2 \mathrm{~A} / 2 \mathrm{~B}$ & $0(0.0)$ & $4(10.8)$ & $0(0.0)$ \\
\hline \multicolumn{4}{|l|}{ Medical history } \\
\hline Hematuria & $16(29.1)$ & 7 (18.9) & $12(21.8)$ \\
\hline Kidney pain & $4(7.3)$ & $4(10.8)$ & $6(10.9)$ \\
\hline Nephrolithiasis & $7(12.7)$ & $2(5.4)$ & $6(10.9)$ \\
\hline Urinary tract infection & $3(5.5)$ & $4(10.8)$ & $4(7.3)$ \\
\hline Anemia & $3(5.5)$ & $4(10.8)$ & $5(9.1)$ \\
\hline Proteinuria & $20(36.4)$ & $12(32.4)$ & $14(25.5)$ \\
\hline \multicolumn{4}{|l|}{ Current medication } \\
\hline ACE inhibitor & $8(14.5)$ & $2(5.4)$ & $3(5.5)$ \\
\hline $\mathrm{ARB}$ & $36(65.5)$ & $17(45.9)$ & $36(65.5)$ \\
\hline ACE inhibitor, ARB, or both & $38(69.1)$ & $18(48.6)$ & $37(67.3)$ \\
\hline Beta-blocker & $7(12.7)$ & $2(5.4)$ & $7(12.7)$ \\
\hline Calcium channel blocker & $23(41.8)$ & $7(18.9)$ & $21(38.2)$ \\
\hline Diuretic & $2(3.6)$ & $0(0.0)$ & $2(3.6)$ \\
\hline
\end{tabular}


Table 1 (continued)

\begin{abstract}
Categorical data are expressed as number $(\%)$. Continuous data are expressed as mean \pm standard deviation. Responders: tolvaptan-treated patients with a net decrease in TKV from baseline to year 3. Non-responders: tolvaptan-treated patients with a net increase in TKV from baseline to year 3

$1 / C r$ reciprocal of serum creatinine, $A C E$ angiotensin-converting enzyme, $A D P K D$ autosomal dominant polycystic kidney disease, $A R B$ angiotensin II receptor blocker, $B M I$ body mass index, $C c r$ estimated creatinine clearance, $C K D$ chronic kidney disease, $C K D$-EPI Chronic Kidney Disease Epidemiology Collaboration, $\mathrm{Cr}$ serum creatinine, $\mathrm{Cys} C$ serum cystatin $\mathrm{C}, e G F R$ estimated glomerular filtration rate, $e G F R-J$ estimated glomerular filtration rate by the Japanese equation based on serum creatinine, $T K V$ total kidney volume

${ }^{\mathrm{a}}$ Ccr calculated by the Cockcroft-Gault formula

beGFR calculated by the CKD-EPI equation modified for Japanese

ceGFR calculated by the Japanese eGFR equation based on Cr, as developed by the Japanese Society of Nephrology

${ }^{\mathrm{d}} \mathrm{CKD}$ stage was classified based on GFR category (in $\mathrm{mL} / \mathrm{min} / 1.73 \mathrm{~m}^{2}$ ): G1, $\geq 90$; G2, 60-89; G3a, 45-59; G3b, 30-44; G4, 15-29; G5, <15

${ }^{\mathrm{e}}$ Patients were categorized into class 1 (typical ADPKD) or class 2 (atypical ADPKD) based on baseline imaging findings, and class 1 was stratified into five subclasses $(1 \mathrm{~A}-1 \mathrm{E})$ based on height-adjusted TKV and age
\end{abstract}

class $1 \mathrm{~B}$ patients ( 6 responders among 10 tolvaptan-treated patients), $38.2 \%$ of class $1 \mathrm{C}$ patients (13 responders among 34 tolvaptan-treated patients), $39.3 \%$ of class 1D patients (11 responders among 28 tolvaptan-treated patients), and $18.8 \%$ of class $1 \mathrm{E}$ patients ( 3 responders among 16 tolvaptan-treated patients). Calcium channel blockers were prescribed in significantly fewer patients in the responder group than in either the placebo $(P=0.0216)$ or the non-responder $(P=0.0490)$ group.

\section{Change in TKV}

The time course of percent change in TKV at each visit is shown in Fig. 3 for each group. Changes in TKV from baseline to each year of follow-up were significantly different between the placebo and responder groups $(P<0.0001)$ and between the responder and non-responder groups $(P<0.0001)$. No statistically significant differences between the placebo and non-responder groups were observed. In the responder group, TKV was decreased in all patients at 12 months, with the decreases maintained throughout 3 years of treatment in all patients, with the exception of one patient at year 2 (Fig. 4).

\section{Predictors of TKV decrease}

The significant predictive factors for TKV decrease with tolvaptan were sex (OR for males 0.25 ; 95\% CI 0.10-0.61; $P=0.0024$ ), height (OR $0.93 ; 95 \%$ CI $0.88-0.98$; $P=0.0063$ ), weight (OR $0.95 ; 95 \%$ CI $0.91-0.98$; $P=0.0050$ ), and body mass index (BMI; OR $0.85 ; 95 \% \mathrm{CI}$ $0.73-0.99 ; P=0.0333$ ) (Table 2). Multiple logistic regression analysis was performed using two factors, sex and BMI. Sex was a significant predictor of TKV response (OR for male sex $0.31 ; 95 \%$ CI $0.12-0.81 ; P=0.0165$ ) (Table 3 ).

\section{Change in kidney function}

Changes in eGFR (mean \pm standard deviation [SD]) from baseline to year 3 in the placebo, responder, and nonresponder groups were $-14.55 \pm 8.26,-9.13 \pm 5.77$, and $-9.31 \pm 9.52 \mathrm{~mL} / \mathrm{min} / 1.73 \mathrm{~m}^{2}$, respectively, by the CKD-EPI equation and $-12.61 \pm 7.23,-8.47 \pm 5.03$, and $-8.58 \pm 8.93 \mathrm{~mL} / \mathrm{min} / 1.73 \mathrm{~m}^{2}$, respectively, by the eGFR-J equation (Table 4 ).

Compared with the placebo group, the decline in eGFR assessed by the CKD-EPI $(P=0.0066, P=0.0032)$ and eGFR-J ( $P=0.0269, P=0.0152)$ equations was significantly suppressed in both the responder and non-responder groups (Fig. 5). No statistically significant difference between the responder and non-responder groups was observed for any biomarker of renal function (eGFR CKD-EPI, eGFR-J, serum creatinine $[\mathrm{Cr}]$, reciprocal of serum creatinine $[1 /$ $\mathrm{Cr}$ ], cystatin $\mathrm{C}$ [CysC], and Ccr) (Table 4). Changes in $\mathrm{Ccr}$ (mean $\pm \mathrm{SD}$ ) from baseline to year 3 in the placebo, responder, and non-responder groups were $-16.67 \pm 11.31$, $-10.81 \pm 9.23$, and $-10.65 \pm 13.73 \mathrm{~mL} / \mathrm{min}$, respectively.

Data from additional analyses for changes in eGFR in class 1 patients and by age are summarized in Online Resources 1 and 2.

\section{Associations between TKV and renal function}

In the placebo group, changes in $\mathrm{Cr}(r=0.5971 ; P<0.0001)$ and CysC $(r=0.5240 ; P<0.0001)$ from baseline to year 3 demonstrated a significant positive correlation with TKV, while Ccr $(r=-0.3110 ; P=0.0208)$ and eGFR CKD-EPI $(r=-0.2811 ; P=0.0376)$ showed a significant negative correlation (Table 5). However, no statistically significant associations between changes in TKV and renal function were observed in either the responder or the non-responder group. 
A

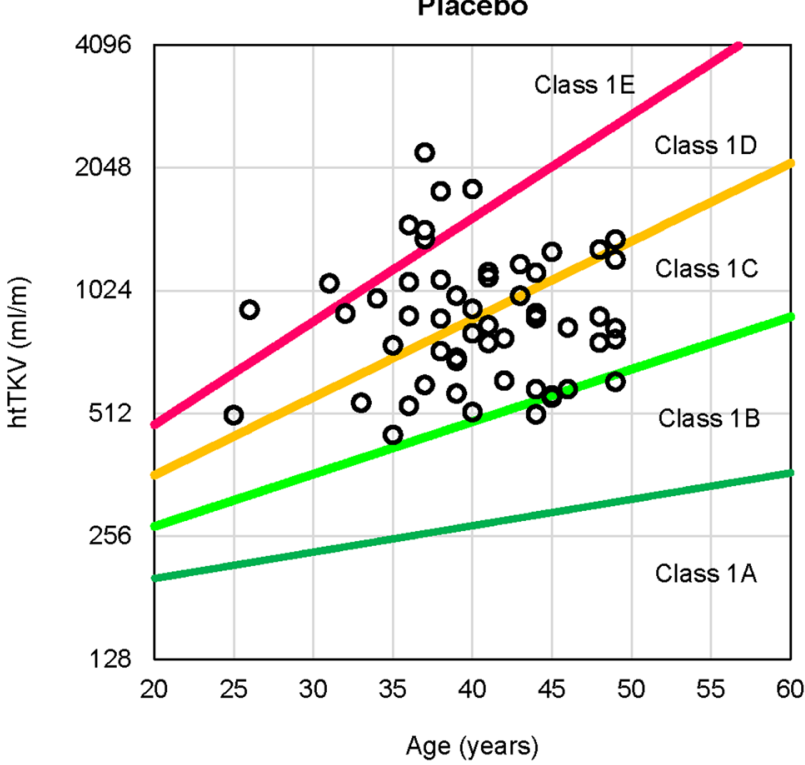

B

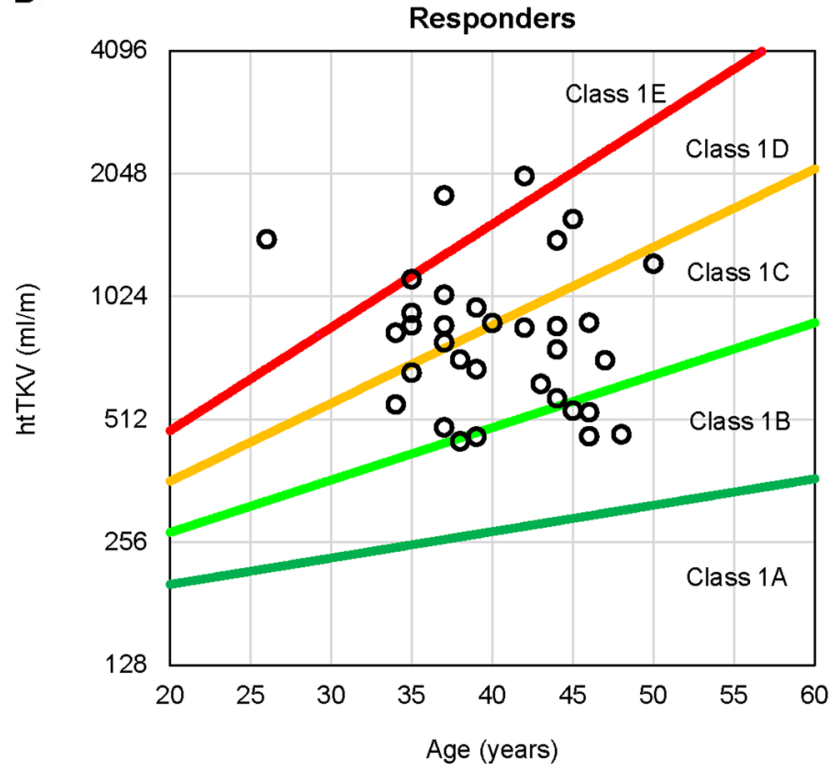

C

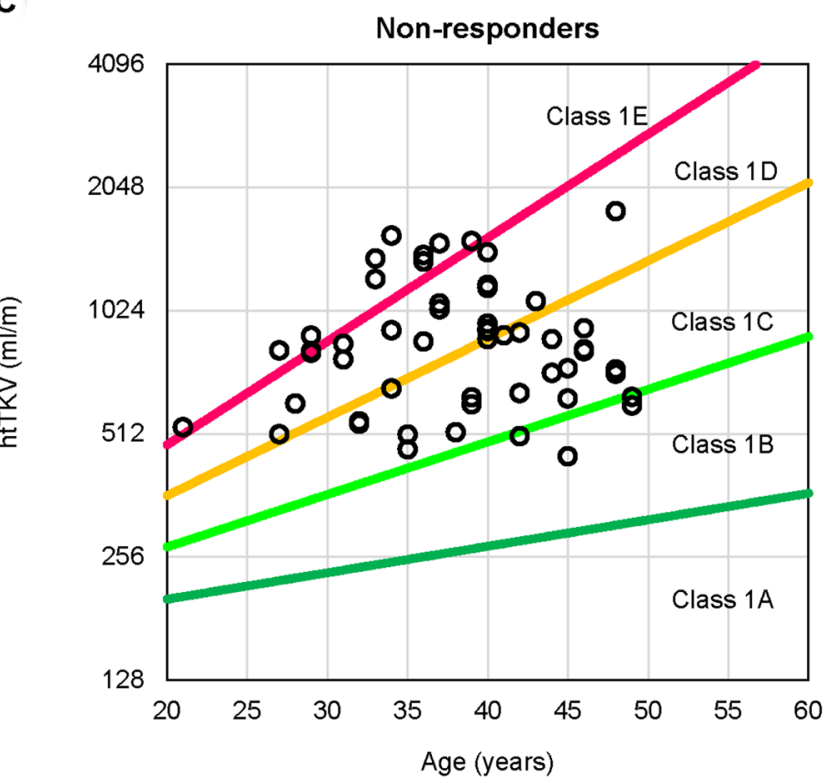

Fig. 2 Risk classification by htTKV and age in class 1 patients. Vertical scale is a $\log _{2}$ scale. Plots are baseline values of htTKV and age. Class 1 was stratified into five subclasses $(1 \mathrm{~A}-1 \mathrm{E})$ based on estimated kidney growth rates: yearly rates of increase of $<1.5 \%$ (1A), 1.5 $3.0 \%$ (1B), 3.0-4.5\% (1C), 4.5-6.0\% (1D), and $>6.0 \%$ (1E), with a

\section{Urine osmolality}

We examined changes in urine osmolality during the trial. Mean \pm SD urine osmolalities in the placebo, responder, and non-responder groups were $475.0 \pm 137.1$, $440.8 \pm 140.6$, and $465.7 \pm 151.2 \mathrm{mOsm} / \mathrm{kg}$, respectively, at baseline and $413.4 \pm 132.5,250.4 \pm 114.6$, and theoretical initial htTKV of $150 \mathrm{~mL} / \mathrm{m}$. Responders: tolvaptan-treated patients with a net decrease in TKV from baseline to year 3. Nonresponders: tolvaptan-treated patients with a net increase in TKV from baseline to year 3. $h t T K V$ height-adjusted total kidney volume, $T K V$ total kidney volume

$247.7 \pm 137.1 \mathrm{mOsm} / \mathrm{kg}$, respectively, at month 36 . Mean urine osmolality decreased significantly more in the tolvaptan-treated groups compared with the placebo group, but there were no differences between the responder group and the non-responder group at 12, 24, and 36 months (Table 6). 


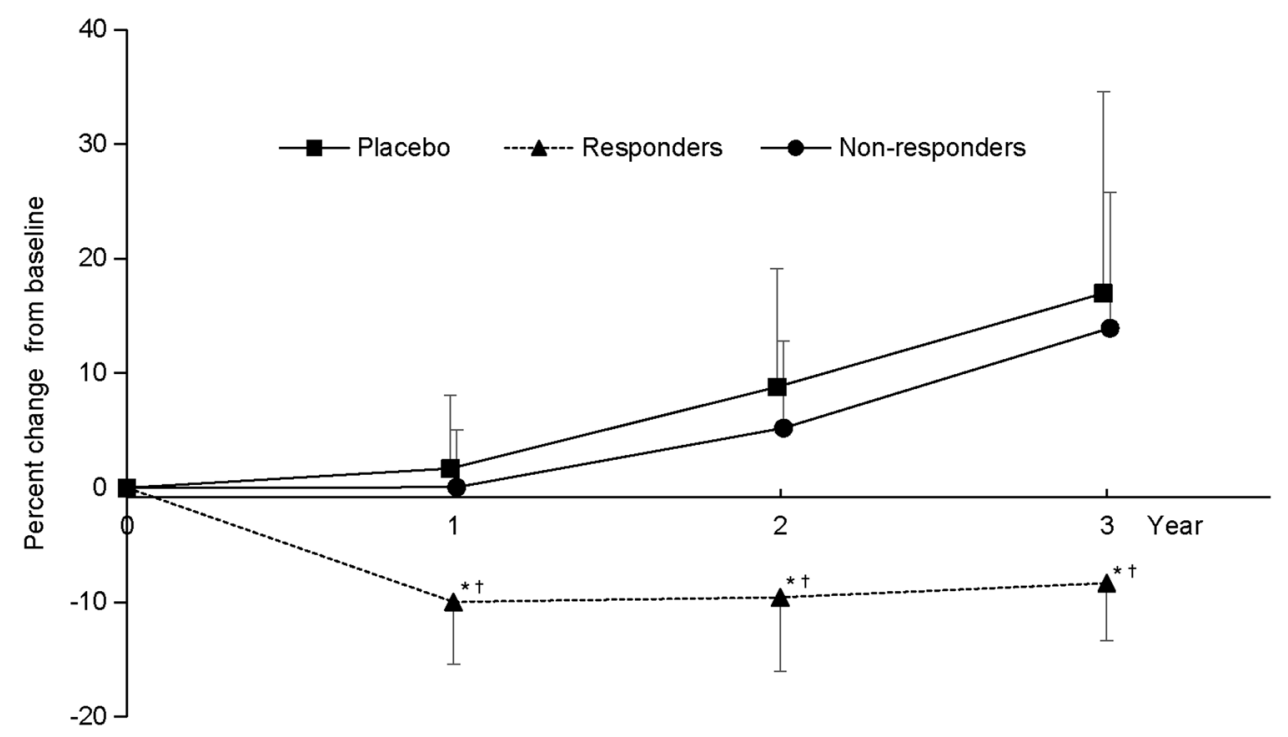

Fig. 3 Time course of change in TKV over 3 years in the placebo, responder, and non-responder groups. Values are expressed as mean and standard deviation. Responders: tolvaptan-treated patients with a net decrease in TKV from baseline to year 3. Non-responders: tolvaptan-treated patients with a net increase in TKV from baseline to year 3. $P<0.0001$ based on Tukey-Kramer's honestly significant difference test comparing percent change in TKV from baseline to each year of follow-up between the placebo and responder groups (*) and between the responder and non-responder groups $\left({ }^{\dagger}\right) . T K V$ total kidney volume
A

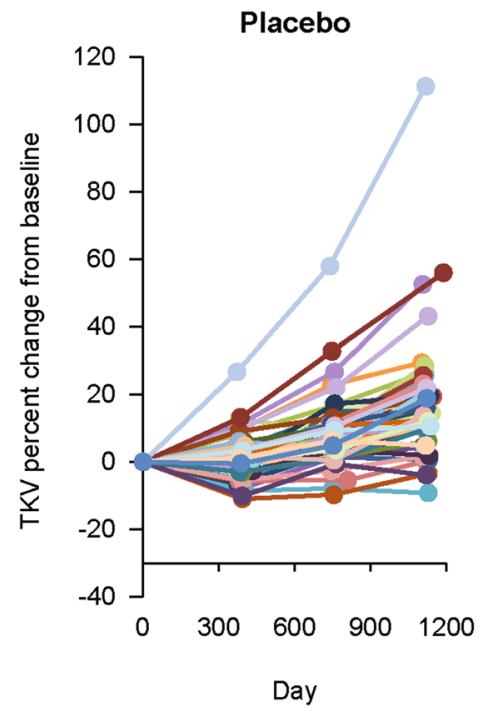

B

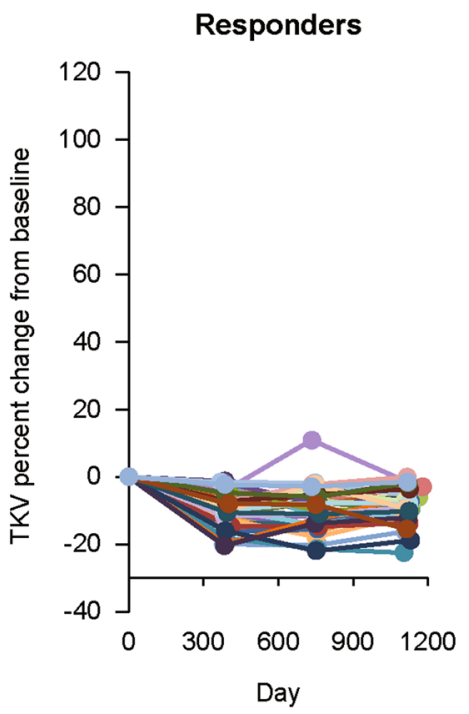

C

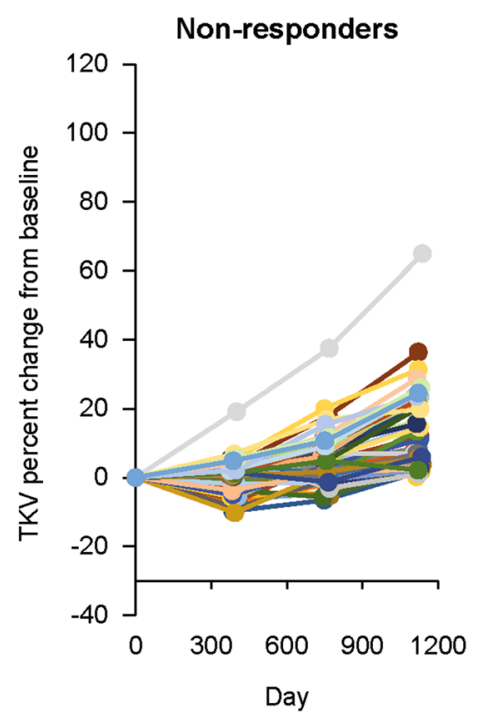

Fig. 4 Time course of TKV in each patient throughout the treatment period. Responders: tolvaptan-treated patients with a net decrease in TKV from baseline to year 3. Non-responders: tolvaptan-treated patients with a net increase in TKV from baseline to year 3. $T K V$ total kidney volume

\section{Discussion}

Mechanisms of cyst expansion in ADPKD and the associated increase in TKV are based on reduced intracellular $\mathrm{Ca}^{2+}$ influx caused by mutations in either PKD1 or PKD2, increased cellular adenosine $3^{\prime}, 5^{\prime}$-cyclic monophosphate
(cAMP) levels, and aberrant Ras/Raf/ERK activation [18]. Tolvaptan blocks the vasopressin $\mathrm{V}_{2}$-receptor, reducing cAMP levels [18]. The progression of ADPKD is characterized by a continuous expansion of cyst volume, a process that was well represented by change in TKV over time in the placebo group of this study (Fig. 3). During longitudinal follow-up in CRISP II, htTKV and GFR exhibited 
Table 2 Univariate analysis of factors predictive of TKV reduction

\begin{tabular}{|c|c|c|c|}
\hline & Odds ratio & $95 \% \mathrm{CI}$ & $P$ value \\
\hline \multicolumn{4}{|l|}{ Demographic characteristic } \\
\hline Sex (male) & 0.25 & $0.10-0.61$ & 0.0024 \\
\hline Age (years) & 1.05 & $0.97-1.12$ & 0.2093 \\
\hline Height (cm) & 0.93 & $0.88-0.98$ & 0.0063 \\
\hline Weight (kg) & 0.95 & $0.91-0.98$ & 0.0050 \\
\hline $\mathrm{BMI}\left(\mathrm{kg} / \mathrm{m}^{2}\right)$ & 0.85 & $0.73-0.99$ & 0.0333 \\
\hline \multicolumn{4}{|l|}{ Stratification factor } \\
\hline Hypertension & 0.51 & $0.20-1.26$ & 0.1453 \\
\hline $\mathrm{Ccr}<80 \mathrm{~mL} / \mathrm{min}$ & 2.36 & $1.00-5.59$ & 0.0509 \\
\hline $\mathrm{TKV}<1500 \mathrm{~mL}$ & 1.69 & $0.64-4.45$ & 0.2859 \\
\hline \multicolumn{4}{|l|}{ Medical history } \\
\hline Hematuria & 0.84 & $0.29-2.37$ & 0.7364 \\
\hline Kidney pain & 0.99 & $0.26-3.78$ & 0.9882 \\
\hline Nephrolithiasis & 0.47 & $0.09-2.45$ & 0.3676 \\
\hline Urinary tract infection & 1.55 & $0.36-6.61$ & 0.5572 \\
\hline Anemia & 1.21 & $0.30-4.85$ & 0.7856 \\
\hline Proteinuria & 1.41 & $0.56-3.52$ & 0.4670 \\
\hline \multicolumn{4}{|l|}{ Current medication } \\
\hline ACE inhibitor & 0.99 & $0.16-6.24$ & 0.9919 \\
\hline ARB & 0.45 & $0.19-1.05$ & 0.0654 \\
\hline ACE inhibitor, ARB, or both & 0.46 & $0.20-1.08$ & 0.0762 \\
\hline Beta-blocker & 0.39 & $0.08-2.00$ & 0.2601 \\
\hline Calcium channel blocker & 0.38 & $0.14-1.01$ & 0.0531 \\
\hline Diuretic & N.A & & \\
\hline \multicolumn{4}{|l|}{ Polycystic kidney disease characteristic } \\
\hline ADPKD risk classification $^{\mathrm{a}}$ & 0.63 & $0.38-1.03$ & 0.0663 \\
\hline Systolic blood pressure (mm Hg) & 0.98 & $0.95-1.01$ & 0.1622 \\
\hline Diastolic blood pressure (mm Hg) & 0.99 & $0.95-1.02$ & 0.3975 \\
\hline Mean blood pressure (mm $\mathrm{Hg}$ ) & 0.98 & $0.95-1.02$ & 0.2665 \\
\hline TKV (mL) & 1.00 & $1.00-1.00$ & 0.5003 \\
\hline Height-adjusted TKV (mL/m) & 1.00 & $1.00-1.00$ & 0.7230 \\
\hline Urine albumin-to-creatinine ratio & 0.97 & $0.93-1.02$ & 0.2589 \\
\hline \multicolumn{4}{|l|}{ Kidney function } \\
\hline $\mathrm{Cr}(\mathrm{mg} / \mathrm{dL})$ & 0.44 & $0.11-1.78$ & 0.2514 \\
\hline CysC (mg/L) & 0.31 & $0.04-2.73$ & 0.2947 \\
\hline Urine osmolality (mOsm/kg) & 1.00 & $1.00-1.00$ & 0.4285 \\
\hline $1 / \mathrm{Cr}\left[(\mathrm{mg} / \mathrm{mL})^{-1}\right]$ & 1.01 & $1.00-1.02$ & 0.1897 \\
\hline $\operatorname{Ccr}(\mathrm{mL} / \mathrm{min})^{\mathrm{b}}$ & 0.98 & $0.96-1.00$ & 0.0503 \\
\hline eGFR CKD-EPI $\left(\mathrm{mL} / \mathrm{min} / 1.73 \mathrm{~m}^{2}\right)^{\mathrm{c}}$ & 1.00 & $0.97-1.02$ & 0.8468 \\
\hline eGFR-J $\left(\mathrm{mL} / \mathrm{min} / 1.73 \mathrm{~m}^{2}\right)^{\mathrm{d}}$ & 0.99 & $0.97-1.02$ & 0.6873 \\
\hline
\end{tabular}

Factors were analyzed by logistic regression

$1 / C r$ reciprocal of serum creatinine, $A C E$ angiotensin-converting enzyme, $A D P K D$ autosomal dominant polycystic kidney disease, $A R B$ angiotensin II receptor blocker, $B M I$ body mass index, $C c r$ estimated creatinine clearance, $C I$ confidence interval, $C K D$-EPI Chronic Kidney Disease Epidemiology Collaboration, $\mathrm{Cr}$ serum creatinine, $C y s C$ serum cystatin C, $e G F R$ estimated glomerular filtration rate, $e G F R-J$ estimated glomerular filtration rate by the Japanese equation based on serum creatinine, N.A. not available, $T K V$ total kidney volume

${ }^{a} \mathrm{ADPKD}$ risk classification was defined on an ordinal scale from class $1 \mathrm{~B}$ to $1 \mathrm{E}$

${ }^{\mathrm{b}} \mathrm{Ccr}$ calculated by the Cockcroft-Gault formula

${ }^{c}$ eGFR calculated by the CKD-EPI equation modified for Japanese
Table 2 (continued)

deGFR calculated by the Japanese eGFR equation based on $\mathrm{Cr}$, as developed by the Japanese Society of Nephrology

Table 3 Multivariate analysis of factors predictive of TKV reduction

\begin{tabular}{llll}
\hline Factor & Odds ratio & $95 \%$ CI & $P$ value \\
\hline Sex $($ male $)$ & 0.31 & $0.12-0.81$ & 0.0165 \\
BMI $\left(\mathrm{kg} / \mathrm{m}^{2}\right)$ & 0.92 & $0.78-1.08$ & 0.2984 \\
\hline
\end{tabular}

Factors were analyzed by logistic regression

$B M I$ body mass index, $C I$ confidence interval, $T K V$ total kidney volume

a significant negative correlation [4]. This phenomenon has also been observed in a Japanese cohort, in which a significant negative correlation between baseline TKV and eGFR slope was observed [19]. Thus, TKV is used as a surrogate biomarker of ADPKD progression [1].

In our study, female sex was a significant positive predictor of tolvaptan's effect in reducing TKV growth. Since there was no modification of tolvaptan dosage for either sex in this study, it is possible that the same dosage may have produced higher serum drug concentrations in females. However, pharmacokinetic analyses in patients with ADPKD have shown that there are no sex differences in the blood concentration of tolvaptan [20]; therefore, we could not define why female sex was identified as a predictor.

In a previous post hoc analysis of TEMPO 3:4, it was reported that baseline urine osmolality influenced disease progression and the response to tolvaptan in patients with ADPKD [21]. The importance of vasopressin is further supported by recent findings on copeptin levels, a surrogate marker for arginine vasopressin (AVP). Copeptin concentrations are higher in men, positively correlate with TKV growth, and predict response to tolvaptan in ADPKD [22, 23]. Subsequent research has confirmed that men have a consistently higher urine osmolality than women [24]. In the present analysis, however, urine osmolality did not predict the effect of tolvaptan in reducing TKV growth. Additionally, there were no differences in urine osmolality at years 1 , 2 , and 3 between the responder and non-responder groups.

ADPKD risk classification is a practical method for evaluating the prognosis of patients with ADPKD [12, 25, 26]. In the model developed by Irazabal and colleagues, rates of TKV growth and eGFR decline increase stepwise from class $1 \mathrm{~A}$ to $1 \mathrm{E}$ in ADPKD with a typical presentation. We assessed if there was any difference in risk class distribution between Japanese patients and the global population. In our analysis, classes $1 \mathrm{~B}, 1 \mathrm{C}, 1 \mathrm{D}$, and $1 \mathrm{E}$ constituted $9.5 \%, 40.8 \%, 30.6 \%$, and $16.3 \%$, respectively, of the total 147 patients (Table 1), which is a similar distribution to that 
Table 4 Changes in kidney function from baseline to year 3

\begin{tabular}{|c|c|c|c|c|c|c|}
\hline \multirow[t]{2}{*}{ Kidney function parameter } & \multicolumn{3}{|l|}{ Group } & \multicolumn{3}{|l|}{$P$ value } \\
\hline & Placebo $(n=55)$ & Responders $(n=37)$ & Non-responders $(n=54)$ & PL vs R & PL vs NR & $\mathrm{R}$ vs NR \\
\hline $\mathrm{Cr}(\mathrm{mg} / \mathrm{dL})$ & $0.28 \pm 0.38$ & $0.15 \pm 0.16$ & $0.17 \pm 0.27$ & 0.0853 & 0.1221 & 0.9311 \\
\hline CysC (mg/L) & $0.20 \pm 0.23$ & $0.10 \pm 0.11$ & $0.14 \pm 0.17$ & 0.0297 & 0.2236 & 0.5334 \\
\hline $1 / \mathrm{Cr}\left[(\mathrm{mg} / \mathrm{mL})^{-1}\right]$ & $-17.90 \pm 12.57$ & $-12.12 \pm 8.84$ & $-11.47 \pm 14.35$ & 0.0785 & 0.0217 & 0.9674 \\
\hline $\operatorname{Ccr}(\mathrm{mL} / \mathrm{min})^{\mathrm{a}}$ & $-16.67 \pm 11.31$ & $-10.81 \pm 9.23$ & $-10.65 \pm 13.73$ & 0.0548 & 0.0237 & 0.9978 \\
\hline eGFR CKD-EPI $\left(\mathrm{mL} / \mathrm{min} / 1.73 \mathrm{~m}^{2}\right)^{\mathrm{b}}$ & $-14.55 \pm 8.26$ & $-9.13 \pm 5.77$ & $-9.31 \pm 9.52$ & 0.0066 & 0.0032 & 0.9943 \\
\hline eGFR-J $\left(\mathrm{mL} / \mathrm{min} / 1.73 \mathrm{~m}^{2}\right)^{\mathrm{c}}$ & $-12.61 \pm 7.23$ & $-8.47 \pm 5.03$ & $-8.58 \pm 8.93$ & 0.0269 & 0.0152 & 0.9970 \\
\hline
\end{tabular}

Data are mean \pm standard deviation. $P$ values based on Tukey-Kramer's honestly significant difference test are shown. Responders: tolvaptantreated patients with a net decrease in TKV from baseline to year 3. Non-responders: tolvaptan-treated patients with a net increase in TKV from baseline to year 3

$1 / C r$ reciprocal of serum creatinine, $C c r$ estimated creatinine clearance, $C K D$-EPI Chronic Kidney Disease Epidemiology Collaboration, $C r$ serum creatinine, $C y s C$ serum cystatin $\mathrm{C}, e G F R$ estimated glomerular filtration rate, $e G F R-J$ estimated glomerular filtration rate by the Japanese equation based on serum creatinine, $N R$ non-responder, $P L$ placebo, $R$ responder, $T K V$ total kidney volume

${ }^{\mathrm{a}} \mathrm{Ccr}$ calculated by the Cockcroft-Gault formula

beGFR calculated by the CKD-EPI equation modified for Japanese

' eGFR calculated by the Japanese eGFR equation based on Cr, as developed by the Japanese Society of Nephrology

A

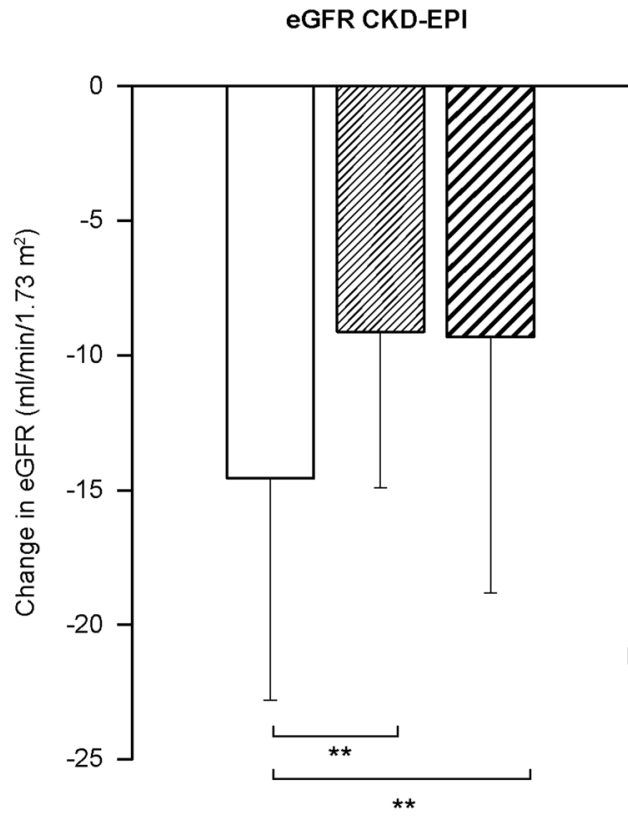

B

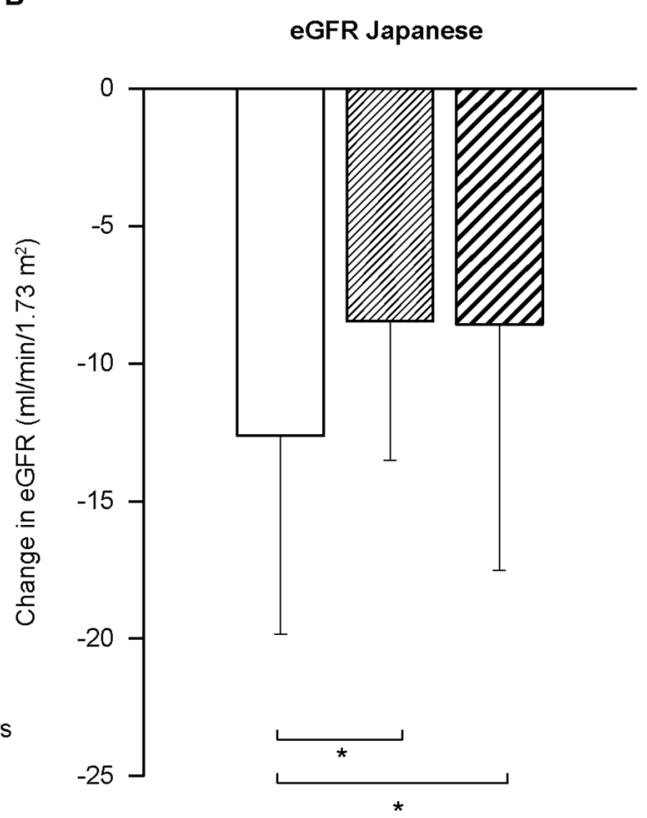

Fig. 5 Change in eGFR from baseline to year 3. Values are expressed as mean and standard deviation. Responders: tolvaptan-treated patients with a net decrease in TKV from baseline to year 3. Nonresponders: tolvaptan-treated patients with a net increase in TKV from baseline to year $3 .{ }^{*} P<0.05$ and ${ }^{* *} P<0.01$ based on TukeyKramer's honestly significant difference test comparing change in

in the TEMPO $3: 4$ global population $(7.6 \%, 38.2 \%, 35.4 \%$, $18.8 \%$ for classes $1 \mathrm{~B}, 1 \mathrm{C}, 1 \mathrm{D}$, and $1 \mathrm{E}$, respectively) [25]. Taken together, our findings indicate no reason to suggest that the effects of tolvaptan in slowing renal function decline are dependent on changes in TKV growth rate. However, the
eGFR from baseline to year 3 between the placebo and responder groups or between the placebo and non-responder groups. $C K D-E P I$ Chronic Kidney Disease Epidemiology Collaboration, eGFR estimated glomerular filtration rate, eGFR Japanese estimated glomerular filtration rate by the Japanese equation based on serum creatinine, $T K V$ total kidney volume

non-responder group included more class $1 \mathrm{E}$ patients compared with the responder group ( $8.1 \%$ vs $23.6 \%$ ). We cannot deny the possibility that TKV growth in the non-responder group might have been much faster and masked the efficacy of tolvaptan. 
Table 5 Correlations between changes in TKV and kidney function

\begin{tabular}{|c|c|c|c|c|c|c|c|c|c|}
\hline \multirow[t]{2}{*}{ Group } & \multirow[t]{2}{*}{ Kidney function parameter } & \multirow[t]{2}{*}{$n$} & \multicolumn{2}{|c|}{ Univariate } & \multirow{2}{*}{$\begin{array}{l}\text { Correlation } \\
\text { coefficient }^{\mathrm{a}} \\
r\end{array}$} & \multicolumn{3}{|c|}{ Regression analysis } & \multirow[t]{2}{*}{$P$ value } \\
\hline & & & Mean & SD & & Estimate & SE & $95 \% \mathrm{CI}$ & \\
\hline \multirow[t]{6}{*}{ Placebo } & $\mathrm{Cr}(\mathrm{mg} / \mathrm{dL})$ & 55 & 0.28 & 0.38 & 0.5971 & 28.02 & 5.17 & 17.65 to 38.39 & $<0.0001$ \\
\hline & CysC (mg/L) & 55 & 0.20 & 0.23 & 0.5240 & 40.72 & 9.09 & 22.49 to 58.96 & $<0.0001$ \\
\hline & $1 / \mathrm{Cr}\left[(\mathrm{mg} / \mathrm{mL})^{-1}\right]$ & 55 & -17.90 & 12.57 & -0.1518 & -0.21 & 0.19 & -0.60 to 0.17 & 0.2687 \\
\hline & $\operatorname{Ccr}(\mathrm{mL} / \mathrm{min})^{\mathrm{b}}$ & 55 & -16.67 & 11.31 & -0.3110 & -0.48 & 0.20 & -0.89 to -0.08 & 0.0208 \\
\hline & eGFR CKD-EPI $\left(\mathrm{mL} / \mathrm{min} / 1.73 \mathrm{~m}^{2}\right)^{\mathrm{c}}$ & 55 & -14.55 & 8.26 & -0.2811 & -0.60 & 0.28 & -1.17 to -0.04 & 0.0376 \\
\hline & eGFR-J $\left(\mathrm{mL} / \mathrm{min} / 1.73 \mathrm{~m}^{2}\right)^{\mathrm{d}}$ & 55 & -12.61 & 7.23 & -0.2333 & -0.57 & 0.33 & -1.22 to 0.08 & 0.0865 \\
\hline \multirow[t]{6}{*}{ Responders } & $\mathrm{Cr}(\mathrm{mg} / \mathrm{dL})$ & 37 & 0.15 & 0.16 & 0.3232 & 10.48 & 5.18 & -0.05 to 21.00 & 0.0510 \\
\hline & CysC (mg/L) & 37 & 0.10 & 0.11 & 0.1922 & 9.13 & 7.88 & -6.86 to 25.11 & 0.2544 \\
\hline & $1 / \mathrm{Cr}\left[(\mathrm{mg} / \mathrm{mL})^{-1}\right]$ & 37 & -12.12 & 8.84 & -0.1750 & -0.10 & 0.10 & -0.29 to 0.09 & 0.3001 \\
\hline & $\operatorname{Ccr}(\mathrm{mL} / \mathrm{min})^{\mathrm{b}}$ & 37 & -10.81 & 9.23 & -0.2161 & -0.12 & 0.09 & -0.30 to 0.07 & 0.1988 \\
\hline & eGFR CKD-EPI $\left(\mathrm{mL} / \mathrm{min} / 1.73 \mathrm{~m}^{2}\right)^{\mathrm{c}}$ & 37 & -9.13 & 5.77 & -0.2967 & -0.26 & 0.14 & -0.55 to 0.03 & 0.0746 \\
\hline & eGFR-J $\left(\mathrm{mL} / \mathrm{min} / 1.73 \mathrm{~m}^{2}\right)^{\mathrm{d}}$ & 37 & -8.47 & 5.03 & -0.1661 & -0.17 & 0.17 & -0.51 to 0.17 & 0.3258 \\
\hline \multirow[t]{6}{*}{ Non-responders } & $\mathrm{Cr}(\mathrm{mg} / \mathrm{dL})$ & 54 & 0.17 & 0.27 & 0.1856 & 8.28 & 6.08 & -3.92 to 20.48 & 0.1791 \\
\hline & CysC (mg/L) & 54 & 0.14 & 0.17 & 0.1764 & 12.46 & 9.64 & -6.88 to 31.81 & 0.2019 \\
\hline & $1 / \mathrm{Cr}\left[(\mathrm{mg} / \mathrm{mL})^{-1}\right]$ & 54 & -11.47 & 14.35 & -0.1788 & -0.15 & 0.11 & -0.37 to 0.08 & 0.1959 \\
\hline & $\operatorname{Ccr}(\mathrm{mL} / \mathrm{min})^{\mathrm{b}}$ & 54 & -10.65 & 13.73 & -0.1139 & -0.10 & 0.12 & -0.34 to 0.14 & 0.4124 \\
\hline & eGFR CKD-EPI $\left(\mathrm{mL} / \mathrm{min} / 1.73 \mathrm{~m}^{2}\right)^{\mathrm{c}}$ & 54 & -9.31 & 9.52 & -0.2302 & -0.29 & 0.17 & -0.62 to 0.05 & 0.0940 \\
\hline & eGFR-J $\left(\mathrm{mL} / \mathrm{min} / 1.73 \mathrm{~m}^{2}\right)^{\mathrm{d}}$ & 54 & -8.58 & 8.93 & -0.2043 & -0.27 & 0.18 & -0.63 to 0.09 & 0.1384 \\
\hline
\end{tabular}

Mean and SD represent changes in kidney function parameters from baseline to year 3. Correlation coefficient, estimate, SE, $95 \%$ CI, and $P$ value show correlations between changes in TKV and kidney function parameters from baseline to year 3. Responders: tolvaptan-treated patients with a net decrease in TKV from baseline to year 3. Non-responders: tolvaptan-treated patients with a net increase in TKV from baseline to year 3

1/Cr reciprocal of serum creatinine, $C c r$ estimated creatinine clearance, $C I$ confidence interval, $C K D$-EPI Chronic Kidney Disease Epidemiology Collaboration, $\mathrm{Cr}$ serum creatinine, $C y s C$ serum cystatin C, $e G F R$ estimated glomerular filtration rate, $e G F R-J$ estimated glomerular filtration rate by the Japanese equation based on serum creatinine, $S D$ standard deviation, $S E$ standard error, $T K V$ total kidney volume

${ }^{a}$ Pearson's correlation coefficient

${ }^{\mathrm{b}} \mathrm{Ccr}$ calculated by the Cockcroft-Gault formula

ceGFR calculated by the CKD-EPI equation modified for Japanese

deGFR calculated by the Japanese eGFR equation based on Cr, as developed by the Japanese Society of Nephrology

Table 6 Changes in urine osmolality from baseline to year 3

\begin{tabular}{|c|c|c|c|c|c|c|}
\hline \multirow{2}{*}{$\begin{array}{l}\text { Urine osmolal- } \\
\text { ity }(\mathrm{mOsm} / \mathrm{kg})\end{array}$} & \multicolumn{3}{|l|}{ Group } & \multicolumn{3}{|l|}{$P$ value } \\
\hline & Placebo & Responders & Non-responders & PL vs R & PL vs NR & $R$ vs NR \\
\hline Baseline & $\begin{array}{l}475.0 \pm 137.1 \\
(n=53)\end{array}$ & $\begin{array}{l}440.8 \pm 140.6 \\
(n=36)\end{array}$ & $\begin{array}{l}465.7 \pm 151.2 \\
(n=55)\end{array}$ & 0.5149 & 0.9398 & 0.6987 \\
\hline Month 12 & $\begin{array}{l}401.2 \pm 160.3 \\
(n=53)\end{array}$ & $\begin{array}{l}214.7 \pm 99.5 \\
(n=36)\end{array}$ & $\begin{array}{l}249.7 \pm 140.9 \\
(n=52)\end{array}$ & $<0.0001$ & $<0.0001$ & 0.4830 \\
\hline Month 24 & $\begin{array}{l}420.1 \pm 160.0 \\
(n=53)\end{array}$ & $\begin{array}{l}239.4 \pm 103.6 \\
(n=34)\end{array}$ & $\begin{array}{l}234.8 \pm 108.3 \\
(n=53)\end{array}$ & $<0.0001$ & $<0.0001$ & 0.9854 \\
\hline Month 36 & $\begin{array}{l}413.4 \pm 132.5 \\
(n=53)\end{array}$ & $\begin{array}{l}250.4 \pm 114.6 \\
(n=36)\end{array}$ & $\begin{array}{l}247.7 \pm 137.1 \\
(n=55)\end{array}$ & $<0.0001$ & $<0.0001$ & 0.9949 \\
\hline
\end{tabular}

Data are mean \pm standard deviation. $P$ values based on Tukey-Kramer's honestly significant difference test are shown. Responders: tolvaptan-treated patients with a net decrease in TKV from baseline to year 3. Non-responders: tolvaptan-treated patients with a net increase in TKV from baseline to year 3

$N R$ non-responder, $P L$ placebo, $R$ responder, $T K V$ total kidney volume 
Several lines of evidence suggest that vasopressin contributes to non-diabetic and diabetic chronic kidney disease progression. Plasma vasopressin levels are increased in animal models and in patients with non-diabetic chronic kidney disease, in animal models of streptozotocin-induced and genetic diabetes mellitus, and in patients with type I and type II diabetes mellitus [27, 28]. Plasma levels of copeptin are inversely correlated with GFR [29]. Previous studies have shown that AVP is associated with the progression of chronic kidney disease. Plasma copeptin levels are associated with a decline in kidney function in recipients of kidney transplant [30], and high plasma copeptin levels are associated with lower GFR in patients with type II diabetes mellitus [31]. Furthermore, treatment with $A V P V_{1 a}$ and $V_{2}$ receptor antagonists has been shown to cause a significant reduction in blood pressure, proteinuria, and glomerulosclerosis in animal models with 5/6 nephrectomy [32]. Although the underlying mechanisms are unknown, inhibiting the AVP $\mathrm{V}_{2}$-receptor may confer a renal protective effect, independent of the kidney volume reduction. Thus, tolvaptan might plausibly be beneficial for patients with ADPKD in whom there is little treatment effect on TKV.

Limitations of this study are its small size and use of a sample from a single ethnic group. Potential differences in genetic features between responders and non-responders warrant further investigation.

Currently, in Japan and other countries, the labeling for tolvaptan in ADPKD stresses its effect on reducing the rate of TKV increase. In the United States, following the Replicating Evidence of Preserved Renal Function: an Investigation of Tolvaptan Safety and Efficacy in ADPKD (REPRISE) trial [33], which did not assess changes in TKV, the Food and Drug Administration approved tolvaptan with an indication to slow renal function decline. In our analysis of the Japanese cohort of TEMPO 3:4, we have shown that tolvaptan suppressed eGFR decline regardless of the effects on TKV growth. Accordingly, we propose that patients receiving treatment with tolvaptan who do not experience a reduction in the rate of TKV growth should not discontinue treatment as there may still be beneficial effects on slowing of renal function decline.

Acknowledgements The authors thank all the patients, investigators, and staff at the participating sites for their support to the study. The authors also thank the following investigators who participated in the TEMPO 3:4 trial: Sekiya Shibazaki, Toshio Mochizuki, Saori Nishio (Hokkaido University Hospital), Sadayoshi Ito (Tohoku University Hospital), Koichi Asahi, Tsuyoshi Watanabe, Tetsuo Kato (Fukushima Medical University Hospital), Eiji Kusano (Jichi Medical School Hospital), Michio Kuwahara, Yusuke Tsukamoto (Shuwa General Hospital), Hajime Hasegawa (Saitama Medical Center), Koichi Kamura (National Hospital Organization Chiba-East Hospital), Naoki Nihei, Yukio Naya (Chiba University Hospital), Kosaku Nitta (Tokyo Women's Medical University Hospital), Yasuhiko Iino (Nippon Medical School Hospital), Sei Sasaki (Tokyo Medical and Dental University
Hospital Faculty of Medicine), Kenmei Takaichi (Toranomon Hospital), Tatsuo Hosoya (The Jikei University Hospital), Kikuo Nutahara (Kyorin University Hospital), Koju Kamata, Kazunari Yoshida (Kitasato University Hospital), Masayuki Endoh (Tokai University Hospital), Yoshifumi Ubara (Toranomon Hospital Kajigaya), Ichiei Narita (Niigata University Medical and Dental Hospital), Yoshihide Fujigaki (Hamamatsu University School of Medicine, University Hospital), Yukio Yuzawa, Satoshi Sugiyama, Yoshiyuki Hiki, Midori Hasegawa (Fujita Health University Hospital), Noriyuki Iehara, Atsushi Fukatsu (Kyoto University Hospital), Koichi Seta, Akira Sugawara (National Hospital Organization Kyoto Medical Center), Eiji Ishimura (Osaka City University Hospital), Mikio Okamura (Ohno Memorial Hospital), Yoshitaka Isaka, Enyu Imai (Osaka University Hospital), Akio Matsubara, Noriaki Yorioka (Hiroshima University Hospital), Kazuhiko Tsuruya (Kyushu University Hospital), and Kimio Tomita (Kumamoto University Hospital). The authors thank Kenji Uehara (Medical Affairs, Otsuka Pharmaceutical Co., Ltd., Japan) for his cooperation in medical writing of the manuscript, and both Kenji Uehara and Hisashi Nagamoto (Medical Affairs, Otsuka Pharmaceutical Co., Ltd., Japan) for quality control of the manuscript. This work was financially supported by Otsuka Pharmaceutical Co., Ltd., Japan, and Otsuka Pharmaceutical Development \& Commercialization, Inc., USA, in terms of the study design; collection, analysis, and interpretation of data; writing of the report; and manuscript preparation.

Author contributions $\mathrm{SH}, \mathrm{SM}, \mathrm{HK}$, and TO contributed to the concept and design of the post hoc analysis; YS contributed to the acquisition and analysis of the data; and SH, SM, HK, TO, YS, KN, and TI contributed to the interpretation of the data, critically revised the manuscript, approved the final manuscript, and agreed to be accountable for all aspects of the manuscript.

\section{Compliance with ethical standards}

Conflict of interest S.H. has received advisory board fees, lecture fees, and grant support as an endowed department from Otsuka Pharmaceutical Co., Ltd. and advisory board fees from Sanofi. S.M. has received lecture fees from Otsuka Pharmaceutical Co., Ltd. and belongs to an endowed department sponsored by Otsuka Pharmaceutical Co., Ltd. H.K. belongs to an endowed department sponsored by Otsuka Pharmaceutical Co., Ltd. T.O., Y.S., and T.I. are full-time employees of Otsuka Pharmaceutical Co., Ltd. K.N. is a former employee of Otsuka Pharmaceutical Co., Ltd.

Research involving human participants TEMPO 3:4 was conducted in accordance with the ethical principles originating in the Declaration of Helsinki and in compliance with good clinical practice guidelines. The protocol was approved by the institutional review board (IRB) at each trial site. The first patient was enrolled in Niigata University Medical and Dental Hospital (IRB approval number: CH19-002a).

Informed consent Written informed consent was obtained from all participating patients.

Open Access This article is licensed under a Creative Commons Attribution 4.0 International License, which permits use, sharing, adaptation, distribution and reproduction in any medium or format, as long as you give appropriate credit to the original author(s) and the source, provide a link to the Creative Commons licence, and indicate if changes were made. The images or other third party material in this article are included in the article's Creative Commons licence, unless indicated otherwise in a credit line to the material. If material is not included in the article's Creative Commons licence and your intended use is not permitted by statutory regulation or exceeds the permitted use, you will 
need to obtain permission directly from the copyright holder. To view a copy of this licence, visit http://creativecommons.org/licenses/by/4.0/.

\section{References}

1. Grantham JJ, Torres VE, Chapman AB, et al. Volume progression in polycystic kidney disease. N Engl J Med. 2006;354:2122-30.

2. Chebib FT, Torres VE. Autosomal dominant polycystic kidney disease: core curriculum 2016. Am J Kidney Dis. 2016;67:792-810.

3. Grantham JJ, Chapman AB, Torres VE. Volume progression in autosomal dominant polycystic kidney disease: the major factor determining clinical outcomes. Clin J Am Soc Nephrol. 2006;1:148-57.

4. Chapman AB, Bost JE, Torres VE, et al. Kidney volume and functional outcomes in autosomal dominant polycystic kidney disease. Clin J Am Soc Nephrol. 2012;7:479-86.

5. Gattone VH 2nd, Wang X, Harris PC, et al. Inhibition of renal cystic disease development and progression by a vasopressin V2 receptor antagonist. Nat Med. 2003;9:1323-6.

6. Torres VE, Wang X, Qian Q, et al. Effective treatment of an orthologous model of autosomal dominant polycystic kidney disease. Nat Med. 2004;10:363-4.

7. Wang X, Gattone V 2nd, Harris PC, et al. Effectiveness of vasopressin V2 receptor antagonists OPC-31260 and OPC-41061 on polycystic kidney disease development in the PCK rat. J Am Soc Nephrol. 2005;16:846-51.

8. Wang $\mathrm{X}, \mathrm{Wu} \mathrm{Y}$, Ward $\mathrm{CJ}$, et al. Vasopressin directly regulates cyst growth in polycystic kidney disease. J Am Soc Nephrol. 2008;19:102-8.

9. Aihara M, Fujiki H, Mizuguchi $\mathrm{H}$, et al. Tolvaptan delays the onset of end-stage renal disease in a polycystic kidney disease model by suppressing increases in kidney volume and renal injury. $\mathrm{J}$ Pharmacol Exp Ther. 2014;349:258-67.

10. Torres VE, Chapman AB, Devuyst O, et al. Tolvaptan in patients with autosomal dominant polycystic kidney disease. N Engl J Med. 2012;367:2407-18.

11. Muto S, Kawano H, Higashihara E, et al. The effect of tolvaptan on autosomal dominant polycystic kidney disease patients: a subgroup analysis of the Japanese patient subset from TEMPO 3:4 trial. Clin Exp Nephrol. 2015;19:867-77.

12. Irazabal MV, Rangel LJ, Bergstralh EJ, et al. Imaging classification of autosomal dominant polycystic kidney disease: a simple model for selecting patients for clinical trials. J Am Soc Nephrol. 2015;26:160-72.

13. Torres VE, Meijer E, Bae KT, et al. Rationale and design of the TEMPO (tolvaptan efficacy and safety in management of autosomal dominant polycystic kidney disease and its outcomes) 3:4 study. Am J Kidney Dis. 2011;57:692-9.

14. Cockcroft DW, Gault MH. Prediction of creatinine clearance from serum creatinine. Nephron. 1976;16:31-41.

15. Horio M, Imai E, Yasuda Y, et al. Modification of the CKD epidemiology collaboration (CKD-EPI) equation for Japanese: accuracy and use for population estimates. Am J Kidney Dis. 2010;56:32-8.

16. Matsuo S, Imai E, Horio M, et al. Revised equations for estimated GFR from serum creatinine in Japan. Am J Kidney Dis. 2009;53:982-92.

17. The International Society of Nephrology. Summary of recommendation statements. Kidney Int Suppl. 2013;3:5-14.

18. Reif GA, Yamaguchi T, Nivens E, et al. Tolvaptan inhibits ERKdependent cell proliferation, $\mathrm{Cl}^{-}$secretion, and in vitro cyst growth of human ADPKD cells stimulated by vasopressin. Am J Physiol Renal Physiol. 2011;301:F1005-13.

19. Higashihara E, Nutahara K, Okegawa T, et al. Kidney volume and function in autosomal dominant polycystic kidney disease. Clin Exp Nephrol. 2014;18:157-65.

20. Lanke S, Shoaf SE. Population pharmacokinetic analyses and model validation of tolvaptan in subjects with autosomal dominant polycystic kidney disease. J Clin Pharmacol. 2019;59:763-70.

21. Devuyst O, Chapman AB, Gansevoort RT, et al. Urine osmolality, response to tolvaptan, and outcome in autosomal dominant polycystic kidney disease: results from the TEMPO 3:4 trial. J Am Soc Nephrol. 2017;28:1592-602.

22. Boertien WE, Meijer E, Li J, et al. Relationship of copeptin, a surrogate marker for arginine vasopressin, with change in total kidney volume and GFR decline in autosomal dominant polycystic kidney disease: results from the CRISP cohort. Am J Kidney Dis. 2013;61:420-9.

23. Gansevoort RT, van Gastel MDA, Chapman AB, et al. Plasma copeptin levels predict disease progression and tolvaptan efficacy in autosomal dominant polycystic kidney disease. Kidney Int. 2019;96:159-69.

24. Perinpam M, Ware EB, Smith JA, et al. Key influence of sex on urine volume and osmolality. Biol Sex Differ. 2016;7:12.

25. Irazabal MV, Blais JD, Perrone RD, et al. Prognostic enrichment design in clinical trials for autosomal dominant polycystic kidney disease: the TEMPO 3:4 clinical trial. Kidney Int Rep. 2016;1:213-20.

26. Irazabal MV, Abebe KZ, Bae KT, et al. Prognostic enrichment design in clinical trials for autosomal dominant polycystic kidney disease: the HALT-PKD clinical trial. Nephrol Dial Transplant. 2017;32:1857-65.

27. Bardoux P, Bruneval P, Heudes D, et al. Diabetes-induced albuminuria: role of antidiuretic hormone as revealed by chronic V2 receptor antagonism in rats. Nephrol Dial Transplant. 2003;18:1755-63.

28. Bardoux P, Martin H, Ahloulay M, et al. Vasopressin contributes to hyperfiltration, albuminuria, and renal hypertrophy in diabetes mellitus: study in vasopressin-deficient Brattleboro rats. Proc Natl Acad Sci U S A. 1999;96:10397-402.

29. Bhandari SS, Loke I, Davies JE, et al. Gender and renal function influence plasma levels of copeptin in healthy individuals. Clin Sci. 2009;116:257-63.

30. Meijer E, Bakker SJ, de Jong PE, et al. Copeptin, a surrogate marker of vasopressin, is associated with accelerated renal function decline in renal transplant recipients. Transplantation. 2009;88:561-7.

31. Villela-Torres ML, Higareda-Mendoza AE, Gómez-García A, et al. Copeptin plasma levels are associated with decline of renal function in patients with type 2 diabetes mellitus. Arch Med Res. 2018;49:36-43.

32. Perico N, Zoja C, Corna D, et al. V1/V2 vasopressin receptor antagonism potentiates the renoprotection of renin-angiotensin system inhibition in rats with renal mass reduction. Kidney Int. 2009;76:960-7.

33. Torres VE, Chapman AB, Devuyst O, et al. Tolvaptan in laterstage autosomal dominant polycystic kidney disease. N Engl J Med. 2017;377:1930-42.

Publisher's Note Springer Nature remains neutral with regard to jurisdictional claims in published maps and institutional affiliations. 